\title{
EFFECT OF COPING STRATEGY AND GANGRENE COMPLICATION ON THE LEVEL OF STRESS IN PATIENTS WITH DIABETES MELLITUS, AT ADI HUSADA HOSPITAL, SURABAYA
}

\author{
Sri Anik Rustini \\ School of Health Sciences (STIKES) Hang Tuah Surabaya
}

\begin{abstract}
BACKGROUND: In many people with diabetes, stress can cause blood glucose levels to rise. Learning strategies to deal with stress may lessen this effect. Having diabetes, and incidence of complication (e.g. gangrene), is in itself a major source of stress. People with diabetes have higher rates of anxiety and depression. Learning how to manage stress and treating these skills as a priority, can help people with diabetes cope with stress more effectively. This study aimed to analyze the effect of problem-focused coping strategies and emotion focused coping as well as complications of gangrene on the stress level in patients with diabetes mellitus.

SUBJECT AND METHODS: This was a cross sectional study, conducted in Adi Husada Kapasari Hospital, Surabaya, East Java. A sample of 40 patients with diabetes mellitus was selected for this study. The dependent variable was stress level. The independent variables were the coping strategy and gangrene complication. The coping strategy was distinguished in two types: (1) Problem-focused coping (PFC); (2) Emotion-focused coping (EFC). A questionnaire was developed to measure coping strategy and level of stress. The data was analyzed by a multiple linear regression.

RESULTS: Level of stress decreased with increasing problem-focused coping $(b=-0.49 ; 95 \% C I=-0.82$ to $-0.17 ; p=0.004)$. Level of stress increased with increasing emotion-focused coping $(\mathrm{b}=0.81 ; 95 \% \mathrm{CI}=0.52$ to $1.11 ; \mathrm{p}<0.001)$, and the incidence of gangrene complication $(b=3.66$; $95 \% \mathrm{CI}=0.59$ to $6.74 ; \mathrm{p}=0.021$ ).

CONCLUSION: Level of stress decreased with increasing problemfocused coping, but increased with increasing emotion-focused coping and the incidence of gangrene complication. Patients and health-social care professionals are suggested to capitalize problem-focused coping strategy to alleviate level of stress in patients with diabetes mellitus.
\end{abstract}

Keywords: problem-focused coping, emotion-focused coping, gangrene, stress, diabetes mellitus 